\title{
STI Treatment-Seeking Behaviors Among Youth in Nigeria: Are There Gender Differences?
}

By Kristin N. Mmari, Ololade Oseni and Adesegun O. Fatusi

Kristin N. Mmari is assistant scientist, Department of Population, Family and Reproductive Health, Johns Hopkins Bloomberg School of Public Health, Baltimore, MD, USA. Ololade Oseni is senior monitoring and evaluation advi-

sor, Family Health International, Abuja, Nigeria. Adesegun O. Fatusi is professor, Department of Community Health, College of Health Sciences, Obafemi Awolowo University, Ile-Ife, Nigeria.

CONTEXT: There is little research on STIs among young people in Nigeria. It is important to determine gender differences in health-seeking behaviors among youth with self-reported STI symptoms.

METHODS: Data from 538 males and females aged 15-24 with at least one STI symptom were drawn from the 2003 and 2005 National HIV/AIDS and Reproductive Health Surveys. Bivariate and multivariate analyses were conducted to determine gender differences among those who had sought treatment for their STI symptoms, and the factors related to seeking treatment from formal health care sources versus informal sources.

RESULTS: A greater proportion of males than of females had sought treatment for their STIs (64\% vs. 48\%). Among those who had sought treatment, $60 \%$ of females had gone to formal sources, most commonly a government clinic; $54 \%$ of males had sought care from informal sources, most commonly a traditional healer. Females had lower odds than males of having sought STI treatment (odds ratio, 0.6). Among both males and females, economic status was positively associated with seeking treatment from a formal source rather than an informal source (2.4-4.2); among females, 22-24-year-olds were more likely than those aged 15-18 to have sought treatment from a formal source (2.5).

CONCLUSION: Programs and policies that aim to increase treatment of STIs among young people in Nigeria need to target males and females differently.

International Perspectives on Sexual and Reproductive Health, 2010, 36(2):72-79.

The World Health Organization (WHO) estimates that more than three million new curable STI infections occur annually among people aged 15-49 worldwide-70\% of those among 15-24-year-olds. ${ }^{1,2}$ STIs can lead to major pregnancy complications, secondary infertility, and severe pain and discomfort. ${ }^{3}$ In addition to being serious diseases in their own right, STIs can increase the risk of HIV acquisition and transmission by a factor of up to 10 .

In Nigeria, research on STIs among young people is limited, although there is some evidence that STIs are indeed a common problem in this population. According to a study conducted in the country's rural southeast, the prevalence of STIs among adolescent females was as high as $17 \% .{ }^{4}$ When only sexually active women were considered, 17-19-year-olds had the highest prevalence of chlamydia (11\%) and candidiasis (26\%), and were also the age-group most likely to have had any STI (44\%); women younger than 17 had the highest prevalence of trichomoniasis (11\%), and nearly $20 \%$ also had symptomatic candidiasis. Another study conducted in urban PortHarcourt confirmed the high rate of STIs among adolescents and reported an overall adolescent STI prevalence rate of $14 \% .^{5}$

On the basis of this evidence, the promotion of prompt and appropriate health-seeking behavior among Nigerian adolescents should be a public health priority; however, very little information exists about whether and where young people seek care for their STIs. Health-seeking be- havior is a highly complex and poorly understood subject, particularly in developing countries, where competing systems of traditional, informal and Western medicine coexist. ${ }^{6,7}$ Evidence from some developing countries suggests that the majority of adolescents who have tested positive for STIs or reported STI symptoms first try to treat their infections themselves or seek treatment from nonprofessional providers (e.g., traditional healers, patent medicine sellers), and only turn to public health clinics or formal health care providers as a last resort. ${ }^{8-11}$ For example, according to a study in Bangladesh, female adolescents with self-reported STIs preferred to seek treatment from a pharmacy, followed by a local healer. ${ }^{12}$ And in Zambia, male and female adolescents went to clinics only after failing to get traditional medicine from a traditional or spiritual healer or other private practitioner, or if traditional treatments did not work. ${ }^{13}$

There are specific reasons why it may be difficult for adolescents to seek treatment for STIs, particularly in formal health care settings. First and foremost, many adolescents lack knowledge and information about infections. According to the 2003 Nigerian Demographic and Health Survey, more than 70\% of 15-19-year-old females and $54 \%$ of same-aged males had no knowledge of any STIs. ${ }^{14}$ In other African settings, young women were especially uninformed about STIs, and had difficulty distinguishing between normal and abnormal vaginal discharge. ${ }^{4}$ Adolescents have also been found to be relatively unconcerned 
about contracting an STI: For example, a study in Zambia found that male youth believed that females are the main carriers of STIs, and that it is a normal part of growing up for a young man to acquire an STI. ${ }^{15}$

In addition to these knowledge and information barriers, many adolescents simply prefer not to get treatment from formal health care providers. According to several studies, adolescents often feel unwelcome, perceive providers as being rude, or are refused services. ${ }^{16-18}$ Adolescents report other barriers to seeking care at public health facilities, including cost, the fear that services are not going to be confidential and the fear of meeting their parents or other adults they know at the health care facility. 7,19

To understand how best to promote STI treatment among Nigerian youth, it is critical that we understand their treatment-seeking behaviors. In particular, we need to know the characteristics of adolescents who seek treatment for STIs and where they go to seek treatment. In Nigeria, very few studies have been conducted to examine these issues. From the few that exist, the evidence suggests that the majority of infected adolescents receive no treatment or inadequate treatment. ${ }^{20}$ According to one study, $43 \%$ of young women who tested positive for an STI had not received any treatment. ${ }^{4}$ Moreover, although vaginal itching was frequently reported, fewer than 3\% of female adolescents had sought treatment of any kind, including traditional medicine.

It is unknown whether these findings also apply to male adolescents in Nigeria. Are health-seeking behaviors the same among male and female adolescents with reported STI symptoms? Do males seek care at the same places as females? What are the factors that predict whether adolescents seek treatment for their STIs, and are these factors the same for males and females? This study aims to answer these questions.

\section{METHODS}

\section{Data and Sample}

The data come from the 2003 and 2005 National HIV/AIDS and Reproductive Health Survey (NARHS), a nationally representative household survey of Nigerian females and males of reproductive age (females aged 15-49 and males aged 15-64). The primary objective of NARHS is to provide information on sexual and reproductive health in Nigeria and data for monitoring the impact of ongoing HIV and family planning behavioral change interventions. The study used a three-level, multistage method to randomly select eligible participants in each of Nigeria's 36 states with equal probability. Each state was first stratified by rural or urban area, followed by random selection of enumeration areas; individual participants were then selected at the household level. ${ }^{21}$

Trained interviewers used a structured questionnaire to ask participants about social and demographic characteristics and various reproductive and sexual health issues, including sexual behaviors, knowledge of HIV and other STIs, condom awareness and use, family planning atti- tudes and utilization, gender-based violence, safe motherhood and communication. The questions were largely derived from the UNAIDS general population HIV and AIDS indicator questionnaire 22 and the Nigeria Demographic and Health Survey. ${ }^{14}$ Independent reviews of the entire survey process were undertaken by technical advisors from the U.S. Agency for International Development, the Department for International Development and WHO. ${ }^{21}$

Of the 8,382 youth (4,007 males and 4,375 females) drawn from the total population of the two surveys, we used data on sexually experienced 15-24-year-olds who reported at least one STI symptom (i.e., genital discharge, genital itching or genital ulcers) in the 12 months prior to interview; 538 respondents ( 162 males and 376 females) met these criteria and were included in the study.

\section{Measures}

Two dependent variables were examined: whether young people had sought medical advice or treatment the last time they experienced genital itching, discharge or ulcers, and if so, whether they went to a formal source (workplace clinic, government clinic or private pharmacy) or an informal source (religious clinic, traditional healer or patent medicine store). Independent variables included age, gender, urban or rural residence, current marital status and religion. In addition, a dichotomous measure of education was based on whether the respondent had ever attended school, and a three-tiered measure of wealth (low, medium and high) was created from questions about the respondent's type of dwelling, household assets, water supply and method of sewage removal. Two sexual behavior variables were included: a dichotomous measure of whether the respondent had had more than one partner in the previous year and a categorical measure of age at sexual debut. Finally, a four-tiered measure of STI knowledge was based on the following three questions: "Have you ever heard of diseases that can be transmitted through sexual intercourse?", "Can STIs prevent a man/woman from fathering a child/getting pregnant in the future?" and "Can you describe any of the symptoms of STIs?" Youth who had never heard of STIs were categorized as having no knowledge; those who had heard of an STI and could describe at least one symptom, but were not aware that it can cause infertility were categorized as having low knowledge; those who had heard of an STI, could describe at least one symptom and were aware that STIs can cause infertility in either men or women were categorized as having medium knowledge; and those who had heard of an STI, could describe at least one symptom and were aware that STIs can cause infertility in both men and women were categorized as having high knowledge.

\section{Statistical Analyses}

For all data analyses, we used Stata statistical analysis package version 10. Distributions of all categorical variables were compared by gender using chi-square tests. Frequencies were calculated and cross-tabulated to compare 
TABLE 1. Percentage distribution of Nigerian youth who reported at least one STI symptom in the 12 months prior to interview, by gender, according to selected characteristics, 2003 and 2005 National HIV/AIDS and Reproductive Health Survey

\begin{tabular}{lccc} 
Characteristic & $\begin{array}{l}\text { All } \\
(\mathrm{N}=538)\end{array}$ & $\begin{array}{l}\text { Males } \\
(\mathrm{N}=162)\end{array}$ & $\begin{array}{r}\text { Females } \\
(\mathrm{N}=376)\end{array}$ \\
\hline Age & & & \\
$15-18$ & 31.0 & 30.9 & 31.1 \\
$19-21$ & 37.2 & 37.7 & 36.9 \\
$22-24$ & 31.8 & 31.5 & 31.9 \\
& & & \\
Religion & & & \\
Islam & 41.3 & 33.3 & 44.7 \\
Christianity & 57.4 & 64.8 & 54.3 \\
Traditional & 0.7 & 1.2 & 0.5 \\
Other & 0.6 & 0.6 & 0.5 \\
& & & \\
Residence & & & \\
Urban & 42.4 & 40.1 & 43.4 \\
Rural & 57.6 & 59.9 & 56.4 \\
& & & \\
Geopolitical zone & & & \\
North West & 25.3 & 17.9 & 28.5 \\
North East & 8.9 & 8.6 & 9.0 \\
North Central & 19.3 & 24.1 & 17.3 \\
South West & 19.5 & 14.8 & 21.5 \\
South East & 8.0 & 9.9 & 7.2 \\
South South & 19.0 & 24.7 & 16.5 \\
& & &
\end{tabular}

Ever attended school

Yes

No

Economic status

Low

Middle

High

Marital status

Married

Single

29.6

70.4

7.4

92.6

No. of sexual partners in last 12 mos.

$\geq 2$

50.4

49.6

28.4

71.6

Age at sexual debut

Married

$<15$

$15-19$

20-24

Cannot recall

Single

$<15$

15-19

20-24

Cannot recall

STI knowledge

None

Low

Medium

High

STI symptom

Genital discharge

Genital itching

Genital ulcer

Sought STI treatment

Yes

No

Total

28.3

59.2

10.1

2.5

8.4

43.7

8.4

39.8

17.8

23.6

17.3

41.3

61.8

65.1

18.3
8.3

75.0

16.7 adolescents who sought any treatment with those who did not, and to identify differences between males and females in each group.

We conducted logistic regression analysis to see if an association existed between individual variables and young peoples' seeking any STI treatment and with their seeking treatment in the formal sector versus the informal sector. The odds ratios presented for each variable in the first set of regression analysis were adjusted for demographic factors, sexual behavior and knowledge of STIs. This model was the most parsimonious, given that it had the lowest Akaike's information criterion value; it was used again in the second set of logistic regressions to assess the influence of the independent variables on seeking health care in the formal versus informal sector. This second set of analyses was done separately for males and females; their odds ratios were then compared.

\section{RESULTS}

\section{Descriptive Statistics}

The mean age of the sample was 19.8 years; males' and females' mean ages were similar (19.9 and 19.8, respectively). Fifty-seven percent of young people were Christian, $41 \%$ Muslim and the remainder were members of either traditional or other religious groups (Table 1). Nearly three-fifths lived in rural areas, and the greatest proportion (25\%) lived in the country's North West zone. There was large geographic variation by gender: The highest proportions of males lived in the South South and North Central zones (25\% and 24\%, respectively), whereas the highest proportions of females lived in the North West and South West zones (29\% and 22\%, respectively). The vast majority of young people had attended school (86\%).

Overall, $30 \%$ of the respondents were married, but marital status differed strongly by gender-nearly $40 \%$ of females were married, compared with only $7 \%$ of males. This gender difference was also reflected in respondents' number of sexual partners: Four in 10 women reported more than one partner in the past year, whereas more than seven in 10 men had had multiple recent partners. Nearly $30 \%$ of married females had had first sex before age 15 , compared with $7 \%$ of single females and $8-11 \%$ of men, which may indicate that a sizeable proportion of young women are married at a very early age. The STI knowledge of young people was fairly high and did not differ by gender. The most common STI symptom reported was genital itching (65\%), followed by genital discharge (62\%) and genital ulcers (18\%). A greater proportion of males than of females sought treatment for their STI symptoms (64\% vs. $48 \%$ ), despite similar levels of STI knowledge.

\section{Bivariate Analyses}

The proportions of young people with genital itching or genital ulcers who had sought STI treatment was significantly greater than the proportions who had not (57\% vs. $43 \%$ and $68 \%$ vs. $32 \%$, respectively-Table 2 ). The majority of males had sought treatment for their STI (64\%); 
however, more than half of females (52\%) had not sought treatment. Seeking treatment was more common than not among 19-21-year-olds (52\% vs. 49\%) and 22-24-yearolds (63\% vs. $37 \%$ ); not seeking treatment was more prevalent among those aged 15-18 (56\% vs. 44\%). In addition, there was some variation in treatment seeking by geopolitical zone: For example, in the South South, 73\% of young people had sought STI treatment and 27\% had not, whereas in the North West, $37 \%$ had sought treatment and 63\% had not. Finally, older age at sexual debut and higher STI knowledge were associated with treatmentseeking behavior.

Among those who had sought STI treatment, a greater proportion of females than of males had done so in the formal health sector ( $60 \%$ vs. $46 \%$-not shown); a greater proportion of males than of females had sought treatment in the informal health sector (54\% vs. 40\%). Within each system of care, there were few gender differences with regard to where young people went for treatment. In the formal health care sector, government health clinics were the most common source of care for both males and females (37\% and $41 \%$, respectively-Table 3, page 76 ), and within the informal health care system, traditional healers were the most common source of care for both genders (39\% and $23 \%$, respectively). However, a greater proportion of females with genital itching than of their male counterparts sought treatment ( $76 \%$ vs. $60 \%$ ), which is somewhat surprising given previous findings that women in general do not seek STI treatment for genital itching because they consider it normal and related to the menstrual cycle. ${ }^{23,24}$ In addition, a greater proportion of young men than of women had sought treatment for genital ulcers (30\% vs. $20 \%$ ), although the finding was only marginally significant $(p<0.06)$. Furthermore, there were gender differences with regard to geopolitical zone, education, marital status and number of sexual partners in the last 12 months: Males who sought treatment were more likely than females to reside in the South South geopolitical zone, have formal education, be unmarried and have had a greater number of recent sexual partners.

\section{Multivariate Analyses}

In logistic regression analyses, few variables were associated with young people's STI treatment-seeking behavior (Table 4, page 77). Females had lower odds than males of having sought STI treatment (odds ratio, 0.6), and respondents aged 22-24 had greater odds than those aged 15-18 of having done so (2.3). In addition, young people living in the North Central, South East and South South zones were more likely than those in the North West to have sought treatment (2.4-5.0).

In gender-specific analyses of treatment seeking by health care sector (formal vs. informal), the only factor associated with males' STI treatment-seeking behavior was economic status: Compared with young men of low economic status, those of middle or high status had greater odds of having sought treatment from a formal source
TABLE 2. Percentage distribution of youth, by STI treatmentseeking behavior, according to selected characteristics

\begin{tabular}{|c|c|c|c|}
\hline \multirow[t]{2}{*}{ Characteristic } & \multicolumn{2}{|c|}{ Sought treatment } & \multirow[t]{2}{*}{ Total } \\
\hline & $\begin{array}{l}\text { Yes } \\
(\mathrm{N}=284)\end{array}$ & $\begin{array}{l}\text { No } \\
(\mathrm{N}=254)\end{array}$ & \\
\hline \multicolumn{4}{|l|}{ STI symptom } \\
\hline Genital discharge & 50.3 & 49.7 & 100.0 \\
\hline Genital itching** & 56.6 & 43.4 & 100.0 \\
\hline Genital ulcer** & 68.4 & 31.6 & 100.0 \\
\hline \multicolumn{4}{|l|}{ Gender** } \\
\hline Male & 64.2 & 35.8 & 100.0 \\
\hline Female & 47.9 & 52.1 & 100.0 \\
\hline \multicolumn{4}{|l|}{ Age $^{* *}$} \\
\hline $15-18$ & 43.7 & 56.3 & 100.0 \\
\hline $19-21$ & 51.5 & 48.5 & 100.0 \\
\hline $22-24$ & 63.2 & 36.8 & 100.0 \\
\hline \multicolumn{4}{|l|}{ Religion } \\
\hline Christianity & 56.3 & 43.7 & 100.0 \\
\hline Other & 48.1 & 51.9 & 100.0 \\
\hline \multicolumn{4}{|l|}{ Residence } \\
\hline Urban & 54.4 & 45.6 & 100.0 \\
\hline Rural & 51.6 & 48.4 & 100.0 \\
\hline \multicolumn{4}{|c|}{ Geopolitical zone** } \\
\hline North West & 36.8 & 63.2 & 100.0 \\
\hline North East & 50.0 & 50.0 & 100.0 \\
\hline North Central & 59.6 & 40.4 & 100.0 \\
\hline South West & 47.6 & 52.4 & 100.0 \\
\hline South East & 55.8 & 44.2 & 100.0 \\
\hline South South & 72.6 & 27.4 & 100.0 \\
\hline \multicolumn{4}{|c|}{ Ever attended school } \\
\hline Yes & 54.1 & 45.9 & 100.0 \\
\hline No & 44.9 & 55.1 & 100.0 \\
\hline \multicolumn{4}{|l|}{ Economic status } \\
\hline Low & 50.0 & 50.0 & 100.0 \\
\hline Middle & 54.9 & 45.1 & 100.0 \\
\hline High & 54.2 & 45.8 & 100.0 \\
\hline \multicolumn{4}{|l|}{ Marital status } \\
\hline Married & 49.7 & 50.3 & 100.0 \\
\hline Single & 54.1 & 45.9 & 100.0 \\
\hline \multicolumn{4}{|c|}{ No. of sexual partners in last 12 mos. } \\
\hline 1 & 53.1 & 46.9 & 100.0 \\
\hline$\geq 2$ & 52.4 & 47.6 & 100.0 \\
\hline \multicolumn{4}{|c|}{ Age at sexual debut** } \\
\hline$<15$ & 55.8 & 44.2 & 100.0 \\
\hline $15-19$ & 55.1 & 44.9 & 100.0 \\
\hline $20-24$ & 75.0 & 25.0 & 100.0 \\
\hline Cannot recall & 40.7 & 59.4 & 100.0 \\
\hline \multicolumn{4}{|l|}{ STI knowledge* } \\
\hline None & 41.7 & 58.3 & 100.0 \\
\hline Low & 51.9 & 48.1 & 100.0 \\
\hline Medium & 49.5 & 50.5 & 100.0 \\
\hline High & 59.5 & 40.5 & 100.0 \\
\hline
\end{tabular}

rather than from an informal source (odds ratios, 4.2 and 3.9, respectively). Among females, those aged 22-24 had greater odds than 15-18-year-olds of having sought treatment from a formal source (2.5). In addition, young women of middle economic status were more likely than those of low status to have sought treatment from the formal health care sector (2.4). 


\begin{tabular}{|c|c|c|c|c|c|}
\hline Characteristic & $\begin{array}{l}\text { Males } \\
(\mathrm{N}=104)\end{array}$ & $\begin{array}{l}\text { Females } \\
(\mathrm{N}=180)\end{array}$ & Characteristic & $\begin{array}{l}\text { Males } \\
(\mathrm{N}=104)\end{array}$ & $\begin{array}{l}\text { Females } \\
(\mathrm{N}=180)\end{array}$ \\
\hline \multicolumn{3}{|l|}{ Health Facility $*,+\neq$} & \multicolumn{3}{|c|}{ Geopolitical zone (continued) } \\
\hline Formal & & & North Central & 25.9 & 19.4 \\
\hline Workplace clinic & 13.5 & 12.8 & South West & 11.5 & 21.1 \\
\hline Government clinic & 36.5 & 41.1 & South East & 6.7 & 9.4 \\
\hline Private clinic & 22.1 & 22.8 & South South** & 33.7 & 21.7 \\
\hline Private pharmacy & 25.9 & 17.2 & \multirow{2}{*}{\multicolumn{3}{|c|}{ Ever attended school* }} \\
\hline Informal & & & & & \\
\hline Religious clinic & 3.9 & 4.4 & Yes & 92.3 & 85.0 \\
\hline Traditional healer** & 39.4 & 23.3 & No & 7.7 & 15.0 \\
\hline Patent medicine store & 18.3 & 15.6 & \multicolumn{3}{|l|}{ Economic status } \\
\hline STI symptom & & & Low & 38.5 & 37.8 \\
\hline Genital discharge & & & Medium & 41.4 & 41.7 \\
\hline Yes & 55.3 & 61.1 & High & 20.2 & 20.6 \\
\hline No & 44.7 & 38.9 & & & \\
\hline Genital itching ${ }^{* *}$ & & & \multicolumn{3}{|l|}{ Married** } \\
\hline Yes & 59.6 & 75.6 & Yes & 9.6 & 38.3 \\
\hline No & 40.4 & 24.4 & No & 90.4 & 61.7 \\
\hline Genital ulcer & & & & & \\
\hline Yes & 29.8 & 20.0 & \multicolumn{3}{|c|}{ No. of sexual partners in last 12 mos.** } \\
\hline No & 70.2 & 80.0 & $\begin{array}{l}1 \\
\geq 2\end{array}$ & $\begin{array}{l}32.7 \\
67.3\end{array}$ & $\begin{array}{l}61.1 \\
38.9\end{array}$ \\
\hline Age & & & \multirow{2}{*}{\multicolumn{3}{|c|}{ Age at sexual debut }} \\
\hline $15-18$ & 25.0 & 26.1 & & & \\
\hline $19-21$ & 34.6 & 37.2 & $<15$ & 12.5 & 16.7 \\
\hline $22-24$ & 40.3 & 36.7 & $\begin{array}{l}15-19 \\
20-24\end{array}$ & $\begin{array}{l}46.2 \\
14.4\end{array}$ & $\begin{array}{l}52.2 \\
11.7\end{array}$ \\
\hline Religion & & & Cannot recall & 26.9 & 19.4 \\
\hline Christianity & 65.4 & 58.9 & \multirow{2}{*}{\multicolumn{3}{|c|}{ STI knowledge }} \\
\hline Other & 34.6 & 41.1 & & & \\
\hline & & & None & 7.7 & 17.8 \\
\hline Residence & & & Low & 25.9 & 21.7 \\
\hline Urban & 37.5 & 47.2 & Medium & 20.2 & 13.9 \\
\hline Rural & 62.5 & 52.8 & High & 46.2 & 46.7 \\
\hline Geopolitical zone & & & Total & 100.0 & 100.0 \\
\hline North West* & 15.4 & 18.9 & & & \\
\hline North East & 6.7 & 9.4 & & & \\
\hline
\end{tabular}

\section{DISCUSSION}

According to our findings, there were large differences in the STI treatment-seeking behavior of young men and women in Nigeria. Males were more likely than females to seek treatment for their symptoms, which is consistent with previous research conducted in Nairobi, Kenya. ${ }^{25}$ From a social and cultural perspective, there are several reasons why this may be. First, females tend to bear the bulk of the stigma attached to STIs, with infections often being perceived as a sign of promiscuity. ${ }^{8}$ As a result, women may choose not to confide in anyone, even if they have an unusual discharge or a sore. Second, the majority of young women who reported at least one STI symptom were married and may have been infected by their husband. Married women-out of fear of possible repercussions-may choose to treat their STIs themselves rather than risk going to a public health facility that might share their information with their husband. ${ }^{26}$ Finally, males might simply experience STIs differently than females. Indeed, as mentioned previously, many women who experience such STI symptoms as vaginal discharge and genital itching do not regard them as serious or as the result of sexual intercourse and, therefore, do not believe that they need to be treated. ${ }^{24,27}$

We also found differences between where young men and women go for STI treatment. Males who sought STI treatment were more likely to go to informal sources, particularly traditional healers, whereas females who sought treatment were more likely to go to formal sources, such as government health clinics. This may be because clinics are often seen as being for women, and males may feel uncomfortable being treated by a female provider. ${ }^{8}$ Traditional healers, on the other hand, may be viewed as being more discreet because they are usually located far away from town and are less busy than government clinics. One study found that access to traditional healers was viewed as being better than access to government clinics. ${ }^{28}$ In addition, there is a widespread belief that traditional medicine is more effective for STIs than Western medicine. ${ }^{29}$ Furthermore, although traditional healers do charge for their services, they may allow clients to pay at least part of their fee later on, as opposed to government clinics, which require full payment at time of treatment. ${ }^{30}$ A previous Nigerian study reported "low cost and speed of both service delivery 


\begin{tabular}{|c|c|c|c|c|c|}
\hline \multirow[t]{3}{*}{ Characteristic } & \multirow{3}{*}{$\begin{array}{l}\text { Sought any treatment } \\
(\mathrm{N}=538) \\
\text { Adjusted }\end{array}$} & \multicolumn{4}{|c|}{ Sought treatment from formal sourcet } \\
\hline & & \multicolumn{2}{|l|}{ Males $(\mathrm{N}=104)$} & \multicolumn{2}{|l|}{ Females $(\mathrm{N}=180)$} \\
\hline & & Unadjusted & Adjusted & Unadjusted & Adjusted \\
\hline \multicolumn{6}{|l|}{ DEMOGRAPHIC } \\
\hline Male (ref) & 1.00 & na & na & na & na \\
\hline Female & $0.56(0.36-0.87)^{* *}$ & na & na & na & na \\
\hline \multicolumn{6}{|l|}{ Age } \\
\hline $15-18$ (ref) & 1.00 & 1.00 & 1.00 & 1.00 & 1.00 \\
\hline $19-21$ & $1.39(0.89-2.18)$ & $0.69(0.25-1.88)$ & $0.45(0.14-1.51)$ & $1.33(0.63-2.83)$ & $1.62(0.70-3.75)$ \\
\hline $22-24$ & $2.33(1.42-3.82)^{* *}$ & $0.64(0.24-1.72)$ & $0.62(0.18-2.14)$ & $2.05(0.95-4.44)$ & $2.45(1.00-5.92)^{*}$ \\
\hline \multicolumn{6}{|l|}{ Marital status } \\
\hline Married (ref) & 1.00 & 1.00 & 1.00 & 1.00 & 1.00 \\
\hline Single & $0.93(0.55-1.56)$ & $3.83(0.77-19.01)$ & $5.72(0.91-35.95)$ & $1.39(0.75-2.56)$ & $1.20(0.50-2.85)$ \\
\hline \multicolumn{6}{|c|}{ Attended school } \\
\hline No (ref) & 1.00 & 1.00 & na & 1.00 & 1.00 \\
\hline Yes & $0.94(0.53-1.67)$ & $\neq$ & na & $1.76(0.77-4.01)$ & $0.81(0.29-2.89)$ \\
\hline \multicolumn{6}{|l|}{ Economic status } \\
\hline Low (ref) & 1.00 & 1.00 & 1.00 & 1.00 & 1.00 \\
\hline Middle & $1.06(0.69-1.64)$ & $3.66(1.46-9.19)^{*}$ & $4.17(1.46-11.93)^{*}$ & $2.54(1.28-5.01)^{*}$ & $2.41(1.09-5.32)^{*}$ \\
\hline High & $0.99(0.59-1.69)$ & $3.52(1.16-10.65)^{*}$ & $3.91(1.09-14.02)^{*}$ & $2.82(1.21-6.61)^{*}$ & $2.26(0.85-5.98)$ \\
\hline \multicolumn{6}{|c|}{ Geopolitical zone } \\
\hline North West (ref) & 1.00 & 1.00 & 1.00 & 1.00 & 1.00 \\
\hline North East & $1.91(0.95-3.84)$ & $\neq$ & na & $0.62(0.19-2.02)$ & $0.77(0.21-2.74)$ \\
\hline North Central & $2.41(1.39-4.17)^{* * *}$ & $1.55(0.44-5.47)$ & $1.67(0.38-7.34)$ & $1.70(0.65-4.49)$ & $1.69(0.60-4.78)$ \\
\hline South West & $1.72(0.98-3.04)$ & $2.33(0.51-10.77)$ & $2.02(0.37-11.07)$ & $1.93(0.74-5.03)$ & $1.49(0.51-4.42)$ \\
\hline South East & $2.39(1.15-5.00)^{* * *}$ & $1.25(0.21-7.62)$ & $2.65(0.29-23.49)$ & $2.89(0.78-10.68)$ & $2.35(0.57-9.64)$ \\
\hline South South & $4.97(2.69-9.16)^{* *}$ & $1.98(0.59-6.64)$ & $2.27(0.55-9.41)$ & $1.04(0.41-2.61)$ & $0.81(0.28-2.33)$ \\
\hline \multirow{2}{*}{\multicolumn{6}{|c|}{$\begin{array}{l}\text { SEXUAL BEHAVIOR AND KNOWLEDGE } \\
\text { No. of sexual partners in last } 12 \text { mos. }\end{array}$}} \\
\hline & & & & & \\
\hline 1 (ref) & 1.00 & 1.00 & 1.00 & 1.00 & 1.00 \\
\hline$\geq 2$ & $1.01(0.65-1.59)$ & $1.62(0.70-3.72)$ & $1.07(0.37-3.06)$ & $1.34(0.72-2.49)$ & $1.25(0.55-2.79)$ \\
\hline \multicolumn{6}{|l|}{ STI knowledge } \\
\hline None (ref) & 1.00 & 1.00 & 1.00 & 1.00 & 1.00 \\
\hline Low & $1.16(0.65-2.06)$ & $0.83(0.16-4.29)$ & $0.93(0.13-6.37)$ & $2.55(0.96-6.74)$ & $2.60(0.87-7.75)$ \\
\hline Medium & $0.99(0.53-1.88)$ & $1.83(0.35-9.72)$ & $1.38(0.19-9.83)$ & $1.70(0.59-4.90)$ & $1.18(0.36-3.83)$ \\
\hline High & $1.66(0.98-2.80)$ & $1.81(0.39-8.44)$ & $2.14(0.35-13.13)$ & $1.75(0.77-3.98)$ & $1.74(0.70-4.31)$ \\
\hline
\end{tabular}

${ }^{*} p<.05 .{ }^{* *} p<.01$. Among those who sought treatment from any source. $¥$ The variables that predicted our outcome perfectly were dropped out in the regression. No males who sought treatment in the formal health sector came from the North East region; all males who sought treatment in formal sector attended school. Note: na=not applicable.

and cure" to explain why male adolescents seek STI treatment from traditional healers. Unfortunately, it is difficult to assess the efficacy of STI treatment from traditional healers because they are discreet, and the likelihood that traditional medicine may do more harm than good is a cause for concern.

Factors other than gender were found to be associated with young people's treatment-seeking behavior. For example, among both males and females, economic status was one of the key characteristics associated with seeking treatment from a formal source rather than an informal source. Among females, older age was also associated with seeking care at a formal health care facility. It may be that older women are more aware than younger women of the reproductive health services that are offered at formal facilities.

Our findings regarding the geographic differences in STI prevalence and in health-seeking behaviors are consistent with the social, cultural and religious contexts of Nigeria. A high proportion of adolescent sexual activity in the North takes place within marriage, whereas in the South, premarital sex is more common. ${ }^{21}$ Also, in the North, it is not uncommon for adolescent girls to be married to much older men, sometimes as a second, third or fourth wife. Polygamy, which is propagated by Islamic religious beliefs, is rare in the South South and South East zones, which have the highest proportions of Christians. Given this context, it is not surprising that smaller proportions of young women sought treatment in the North West than in the South South or South East, as religious and cultural factors in these areas strongly prohibit women from seeking health care services without the authority or presence of their husbands. Moreover, sexual and reproductive health knowledge and access to related health services are generally lower in the North East and North West than in other zones. ${ }^{14,31}$ 
There are a few study limitations that should be noted. First, the data are based on self-reports of STI symptoms, which is particularly problematic for young women, given that many of the symptoms are fairly common and some, such as genital itching, may be unrelated to STIs. However, a greater proportion of females with genital itching than of their male counterparts sought treatment (76\% vs. 60\%), which is somewhat surprising given previous findings that women in general do not seek STI treatment for genital itching because they consider it normal and related to the menstrual cycle. ${ }^{23,24}$ In addition, few young people reported having had any STI symptoms, and because of the small sample, the findings must be considered with caution.

Despite these limitations, our findings have important implications for public health in Nigeria. Foremost, the results highlight the need to target males and females differently for STI treatment services. STI services in the majority of adolescent reproductive health programs are provided as part of a wider package of reproductive health services. Alternatively, STI diagnosis and treatment have been integrated into preexisting antenatal, family planning, postabortion and, in some cases, outpatient services. Although such delivery models may be beneficial to females, they could be having the opposite effect on males by placing STI services in female-oriented settings. Thus, programs and policies aimed at making males more comfortable in government clinics need to be developed, to draw them from such informal sources of care as traditional healers. It may be useful to develop male-only clinics or to designate certain sections of health facilities where males could be treated by male doctors and nurses. In addition, reproductive health communication programs and printed materials that contain images of young men may help promote clinics as male-friendly spaces.

On the other hand, although females were more likely than males to seek STI treatment from formal sources rather than informal ones, they were far less likely than males to seek treatment at all, particularly in the North West zone. Consequently, targeted programs and policies should be developed to promote STI treatment seeking among young women, which could include education about symptom terminology, rather than disease terms, and lessons for women on how to discuss STI symptoms with someone they trust.

Because socioeconomic status was a significant predictor of adolescents' decision to seek treatment at government clinics, new cost-effective strategies may need to be developed to attract adolescents to these locations. One such strategy developed in other contexts is the targeted distribution of vouchers that entitle the holder to a no-cost service at a private or public clinic. Such voucher programs have been successfully used in Nicaragua and in Kenya. ${ }^{32}$

Finally, our findings suggest that there is a need to find ways to work with traditional healers to treat adolescents effectively. A good approach would be to educate traditional healers to recognize various STIs and to require them to provide basic treatment and refer adolescents to formal systems of care. In performing this role, they would be provided with clear guidelines about specific formal treatment centers and health care providers that would see their clients. ${ }^{20}$

\section{REFERENCES}

1. Adler MW, Sexually transmitted disease control in developing countries, Genitourinary Medicine, 1996, 72(1):83-88.

2. World Health Organization (WHO), Weekly Epidemiological Records, 1998, Vol. 73, No. 26.

3. WHO, Global Prevalence and Incidence of Selected Curable Sexually Transmitted Infections: Overview and Estimates, Geneva: WHO, 2001

4. Brabin L et al., Reproductive tract infections and abortion among adolescent girls in rural Nigeria, Lancet, 1995, 345(8945):300-304.

5. Ikimalo J et al., Sexually transmitted infections among Nigerian adolescent schoolgirls, Sexually Transmitted Infections, 1999, 75(2):121

6. Kleinman A, Patients and Healers in the Context of Culture: An Exploration of the Borderline Between Anthropology, Medicine, and Psychiatry, Berkeley, CA, USA: University of California Press, 1980.

7. Mmari K and Magnani R, Does making clinic-based reproductive health services more youth-friendly increase service use by adolescents? Evidence from Lusaka, Zambia, Journal of Adolescent Health, 2003, 33(4):259-270

8. Dehne K and Riedner G, Sexually Transmitted Infections Among Adolescents: The Need for Adequate Health Services, Geneva: WHO, 2005.

9. Brugha R and Zwi A, Sexually transmitted disease control in developing countries: the challenge of involving the private sector, Sexually Transmitted Infections, 1999, 75(5):283-285.

10. Msiska R et al., Understanding lay perspectives: care options for STD treatment in Lusaka, Zambia, Health Policy and Planning, 1997, 12(3):248-252.

11. Nichter M, Self-medication and STD prevention, Sexually Transmitted Diseases, 1996, 23(5):353-356.

12. Barkat A et al., Adolescent Sexual and Reproductive Health in Bangladesh: A Needs Assessment, Dhaka, Bangladesh: International Planned Parenthood Federation and Family Planning Association of Bangladesh, 2000

13. Webb D, Adolescence, Sex and Fear: Reproductive Health Services and Young People in Urban Zambia, Lusaka, Zambia: Central Board of Health/United Nations Children's Fund, 1997.

14. National Population Commission (NPC) and ORC Macro, Nigeria Demographic and Health Survey 2003, Calverton, MD, USA: NPC and ORC Macro, 2004

15. Zambezi R et al., Adolescent Sexual Reproductive Health in Peri-Urban Lusaka, Lusaka, Zambia: CARE International, 1996.

16. Mfono Z, Teenage contraceptive needs in urban South Africa: a case study, International Family Planning Perspectives, 1998, 24(4):180-183.

17. Kim YM, Marangwanda C and Kols A, Quality of counselling of young clients in Zimbabwe, East African Medical Journal, 1997, 74(8):4-5

18. Huntington D, Lettenmaier C and Obeng-Quaidoo I, User's perspective of counseling training in Ghana: the "Mystery Client" trial, Studies in Family Planning, 1990, 21(3):171-177.

19. Temin MJ et al., Perceptions of sexual behavior and knowledge about sexually transmitted diseases among adolescents in Benin City, Nigeria, International Family Planning Perspectives, 1999, 25(4):186$190 \& 195$.

20. Ogunbanjo BO, Sexually transmitted diseases in Nigeria: a review of the present situation, West African Journal of Medicine, 1989, $8(1): 42-49$

21. Fatusi A and Blum RW, Predictors of early sexual initiation among a nationally representative sample of Nigerian adolescents, BMC Public 
Health, 2008, 8:136.

22. ORC Macro and Measure DHS, HIV/AIDS Survey Indicator Database, <http://www.measuredhs.com/hivdata/start.cfm>, accessed Jan. 3, 2008

23. Meyer-Weitz A et al., The determinants of health care seeking behavior of adolescents attending STD clinics in South Africa, Journal of Adolescent Health, 2000, 23(6):741-752.

24. Meyer-Weitz A et al., The socio-cultural context of STDs in South Africa: implications for health education programmes, AIDS Care, 1998, 10(2):39-55

25. Voeten $\mathrm{H}$ et al., Gender differences in health care-seeking behavior for sexually transmitted disease: a population-based study in Nairobi, Kenya, Sexually Transmitted Diseases, 2004, 31(5):265-272.

26. Ezumah NN, Gender issues in the prevention and control of STIs and HIV/AIDS: lessons from Awka and Agulu, Anambra State, Nigeria, African Journal of Reproductive Health, 2003, 7(2):89-99.

27. Fonck K et al., Health seeking and sexual behaviors among primary healthcare patients in Nairobi, Kenya, Sexually Transmitted Diseases, 2002, 29(2):106-111.

28. Marchand C, Can the STI Epidemic Be Addressed Through the Private Sector: A Review of the Evidence, Geneva: WHO, 2000

29. Green EC, AIDS and STD in Africa, Bridging the Gap Between Traditional Healing and Modern Medicine, Boulder, CO, USA: Westview Press, 1994.

30. Akinnawo E and Oguntimehin F, Health-seeking behavior of STD patients in an urban area of southwest Nigeria: an exploratory study, Health Transition Review, 1997, 7(Suppl.):307-313.

31. Federal Ministry of Health, Nigeria, 2008 National HIV/Syphilis Sero-prevalence Sentinel Survey Among Pregnant Women Attending Antenatal Clinics in Nigeria, Abuja, Nigeria: Federal Ministry of Health, 2008.

32. WHO, Protecting Young People from HIV and AIDS: The Role of Health Services, Geneva: WHO, 2004.

\section{RESUMEN}

Contexto: Hay poca investigación sobre las ITS entre las personas jóvenes en Nigeria. Es importante determinar las diferencias de género en los comportamientos de búsqueda de atención a la salud entre los jóvenes que reportan síntomas de ITS. Métodos: Datos de 538 hombres y mujeres de 15-24 años de edad, con al menos un sintoma de ITS, se obtuvieron de las Encuestas Nacionales de VIH/SIDA y Salud Reproductiva (conocido por sus siglas en inglés, NARHS) de 2003 y 2005. Mediante análisis bivariado y multivariado, se determinó las diferencias de género entre los que habian buscado tratamiento para sus sintomas de ITS; y los factores relacionados con la búsqueda de tratamiento en fuentes de servicios de salud formales versus fuentes informales.

Resultados: Se encontró que una mayor proporción de hombres que de mujeres habia buscado tratamiento para sus ITS (64\% vs. 48\%). Sin embargo, entre las y los jóvenes que habí- an buscado tratamiento, una mayor proporción de mujeres que de hombres acudió a fuentes formales (60\% vs. 46\%); las fuentes más comúnmente usados eran las clínicas del gobierno entre las mujeres, y los curanderos entres los varones. Las mujeres tuvieron menor probabilidad que los hombres de haber buscado tratamiento para ITS (razón de momios, 0.6). Tanto entre los hombres como entre las mujeres, la condición económica se asoció positivamente con la búsqueda de tratamiento de una fuente formal de servicios, en vez de una informal (2.4-4.2); entre las mujeres, las de 22-24 años tuvieron mayor probabilidad que las de 15-18 años de haber buscado tratamiento de una fuente formal (2.5).

Conclusión: Los programas y políticas que buscan aumentar el tratamiento de las ITS en la gente joven de Nigeria, necesitan dirigir acciones a hombres y mujeres de manera diferenciada.

\section{RÉSUMÉ}

Contexte: La recherche sur les IST parmi les jeunes du Nigéria n'est guère développée. Il importe de déterminer les différences de genre dans les comportements de recherche de soins parmi les jeunes présentant des symptômes d'IST autodéclarés.

Méthodes: Les données relatives à 538 hommes et femmes de 15 à 24 ans présentant au moins un symptôme d'IST ont été extraites des enquêtes nationales sur le $\mathrm{VIH} /$ sida et la santé génésique (NARHS) de 2003 et 2005. Des analyses bivariées et multivariées ont été menées pour déterminer les différences de genre parmi les jeunes qui avaient cherché à faire soigner leurs symptômes d'IST et les facteurs relatifs à la recherche d'un traitement auprès de sources de soins de santé formelles ou informelles.

Résultats: Les hommes avaient cherché en plus grande proportion à faire traiter leur IST (64\% vs 48\% des femmes). Parmi les jeunes qui s'étaient fait soigner, 60\% des femmes s'étaient adressées à des sources formelles, le plus généralement une clinique publique, et 54\% des hommes avaient consulté des sources informelles, le plus souvent un guérisseur traditionnel. Les femmes présentent une plus faible probabilité de recherche de traitement d'IST (rapport de probabilités, 0,6). Pour les hommes comme pour les femmes, le rang économique est associé positivement à la recherche de soins auprès d'une source formelle plutôt qu'informelle (2,4-4,2); parmi les femmes, celles de 22 à 24 ans se révèlent plus susceptibles que celles de 15 à 18 ans de s'être adressées à une source formelle $(2,5)$.

Conclusion: Les programmes et politiques visant à accroître le traitement des IST parmi les jeunes du Nigéria doivent cibler différemment les hommes et les femmes.

Author contact:kmmari@jhsph.edu 